\title{
Editorial
}

\section{The Editor takes leave}

Diabetologia is on the move. A circulation of over 7000 copies, an influx of about 800 manuscripts per year, an impact factor of 5.4 in 1996: with these credentials, our journal goes back up north. In stately Vienna under the wings of the imperial eagle, Professor Werner Waldhäusl is ready to receive it and take it into the next millennium.

Clearly I feel sad and anxious, like any parent watching his child depart. Adoptive and temporary parents, my co-editors and myself, but still parents. You don't handle 3000 papers, call on 9000 colleagues to review, and send to print 6000 pages without a feeling of relatedness growing out of countless hours of work. Clearly I shall miss the time with Diabetologia, especially as I sense that in the future those hours will be filled with other, probably less interesting work.

Has it been worth it? Yes, definitely. To explain why colleagues should consider the job of editor (when it is next advertised), I shall draw up my personal balance. On the negative side, hundreds of authors that I have disappointed by the ominous rejection formula, legions of colleagues that I have pestered to volunteer written opinions, the team in my lab that have felt neglected (or relieved?), family events that I have miserably missed. To all involved, I can only apologise: for the mistaken judgements as much as for the dinners that went cold. On the positive side, however, there are some grand items. First, I have learned much, inadvertently as if by osmosis, and with a time advantage that, in an era of fast communication, is a plus. Second, I have got to know many people, first by associating names with key words, next by recognising styles (and idiosyncrasies), finally (often) by matching voices or faces to names and ways. Third, I have had protracted opportunity to exercise fairness. Being no less opinionated than authors and referees coming through Diabetologia, I found it sane discipline to try and forgo biases and preferences for the sake of objectivity. Though the results were not guaranteed, there has been a special pleasure in exploring the reaches (and costs) of intellectual honesty a few times every day. Last, but not least, the unselfishness and loyalty with which my closest collaborators, here in Pisa and elsewhere, have helped: through them I have appreciated the difference between individual scientists and a scientific community, cultured beta-cells the former, intact pancreas the latter.
At this point, perhaps a few readers would be curious of whether the experience with Diabetologia has taught me any general lesson. For them here follow some thoughts, with no pretence of organised reasoning or stance.

Diabetology has expanded hugely. From beta-cell function, diabetes research has spread to the whole body. As a consequence, disease mechanisms have overflowed from the classical hormone-receptor interaction to include the immune system, the endothelium, complex nervous functions, and the genome. The technology to assess end-organ damage has then diversified phenomenally, borrowing from neurology, cardiology, nephrology and other specialties. Moreover, the strong dependence of diabetes on aging and obesity has multiplied its quantity in populations that live longer and get progressively heavier. Finally, the high risk that diabetes carries for the development of atherosclerosis has tightly linked hyperglycaemia with cardiovascular diseases, the leading cause of death in westernised societies.

Thus, numbers have run up along several axes: predisposing conditions, etiological factors, mechanisms, interactions, diagnostic methods, treatments, affected individuals, and, last but not least, expenses. A multidimensional deploy, i.e., an explosion. Fatefully, this happens at a time of 'evidence-based medicine'. Bashfully, I confess I do not quite understand the origin and intent of this neologism. Medicine, I thought, has consistently attempted to act on the basis of evidence whenever there was any; when there was none, doctors tried to help using tradition or experience, i. e., empirically. Perhaps, there is an innuendo that the quality of much past evidence was poor, and better standards of proof are now achievable. This, however, would be post-hoc judgement, tinted with arrogance. Maybe evidence-based medicine is an exorcism against a perceived threat: by unorthodox medicine, by the powerful pharmaceutical industry, or by malpractice lawyers. Whatever the case, from an editor's perspective evidence-based medicine so far has eminently looked like 'clinical trialling'. For every question, a trial: parallel or cross-over, intention-to-treat or otherwise, head-to-head or bi-factorial, but always, and absolutely, a large, prospective, controlled, randomised, long-term trial. Ever more trials are needed to support any statement (no matter 
how peripheral or obvious), and where there are several already, meta-analysis is the thing to do. This new wave is already spinning off some curious consequences. Thus, trendy academicians and would-be opinion-makers show off a growing jungle of acronyms that stand for clinical trials (e.g., Mr DIGAMI from the WEST-OF-SCOTLAND would HOPE to take CARE of MONICA with HOT GUSTO). Certain well-informed doctors, on the other hand, are telling trial patients, whom chance allotted to placebo, that their high glucose is destined to regress to the mean, or, to those on the active drug, that their hypoglycaemia is only $0.3 \%$ per year anyway, or, when they make it through the trial, that they represent survival bias. On a bad day, one can foresee a scenario in which there will not be enough diabetic patients for all desirable trials, when patients will rather be cases than persons, and when being in a clinical trial will be the cheapest way for a patient to get treatment (or attention). On a good day, on the other hand, one must plainly reason that (a) with a multifactorial disease like diabetes the number of permutations rises very, very quickly with the number of factors to be tested, (b) trials provide indirect (ex adjuvantibus) evidence, while proof only emerges from mechanisms, and (c) the money that big trials use up is shunted away from research and care. The latter point is annoyingly evident in any system with finite resources. We all would hope not to get carried away along the 'trialist track' under the pretext of evidence-based medicine. Time, however, makes more converts than reason, and there are worrisome signals. One is represented, for a change, by yet another word: globalisation. These days, everything is global. Markets are strangely global, e.g., Italians eat oranges grown in Sicily and imported through Israel. Finances are dangerously global, e.g., if Mr George Soros is reported to sneeze dozens of companies close down business in the Far East. While language is globalising towards an anglicised gibberish, electronic communication is working out a true global village, e.g., Mr Bill Gates is developing an electronic device which, as you step into the house, switches on the $\mathrm{TV}$, recites the phone messages, shows your bank account on a screen, fills the bathtub, and starts the microwave oven to warm up the pizza (manufactured in Hong Kong). One gigantic electronic prosthesis, a digital family is what may be in store for us. Medicine is all but immune to this infection. As your diabetic patient walks into the office, your mind is supposed to quickly scan (a) criteria set forth by the latest committee, (b) flow charts prepared by the Diabetic Association, and (c) recommendations issued by lastweek's consensus conference, all this before you even look at the person. This is a form of globalisation, with the doctors as terminals of one large mainframe machine distributing health standards confectioned by experts. By its nature, evidence-based med- icine tends to globalised medicine: to be worth their cost the results of a proper trial should be translated into clinical recommendations and quickly adopted by the entire medical community. The latter, however, is famously slow to digest new knowledge. The long reaction time ( $=$ time difference between what medical science indicates and what most doctors do) may have all kinds of unpredicted consequences.

Admittedly, there is a quota of paranoia in the above considerations, but I know of an antidote, which will be my parting little present to the readers of Diabetologia. I am the fortunate son-in-law of a sweet little lady of 72 years, by the name of Celestina (nomen atque omen). She is the busiest person I know, industriously carrying out one domestic task after another all day long. In the evening, she sits before the TV, and falls asleep with extraordinary ease. I have maliciously timed the lag-phase between sitting and leaning sideways in peaceful doze at $75 \pm 10$ seconds (mean $\pm \mathrm{SEM}$, variation coefficient of $30 \%$ ). This habit would not be unusual considering her long days and the depressing quality of what passes on the screen. Once in a while, however, she watches with unfailing attention. While at first I thought of a bimodal distribution of my mother-in-law's attention span, I then made the amazing discovery that, infallibly when she does watch something, it is something good, worth seeing for one reason or another. Baffled by this finding, I have investigated it further. The format, be it news, movie, reportage or talk show, does not seem to matter; nor is there a particular subject (sex, violence, religion) or tone (romantic, matter-offact, nostalgic) that consistently attracts her attention. In careful, if covert, observations, I have also ruled out season, composition and time of antecedent dinner, and number and conversation of other onlookers as significant factors. After considering a range of possible theories, I have reached the conclusion that my mother-in-law just 'knows' when to keep the mind alert and when to rest it. One may call this intuition, i. e., subconscious deduction, of what is fact and what is noise. Alternatively, it may reflect the evolution of a down-to-earth attitude under the pressure of a long difficult life in which real problems did not leave much room for nonsense. Whatever the explanation, it is clear that my mother-in-law applies the criteria of reality and parsimony to selectively alert her attention to the TV menu in much the same way as she does to run the household. This mode, 'the Celestina way', does not admit globalisation as it sticks to the particular truth, and is not prone to inducements of any kind. She would drive Mr Gates crazy.

Farewell Diabetologia, and Merry Christmas to all its readers

Ele Ferrannini

Pisa, 31 December 1997 